\title{
Compreensões dos processos de manufatura e suas implicações contábeis mediada por simulação didática
}

\author{
Cristiano Henrique Antonelli da VeigA* \\ Marcella Alves da Silva** \\ Bruna Cristina SiLvério Diniz*** \\ Gabriela Cardoso Souza Lopes $* * * *$
}

\begin{abstract}
RESUMO
Este estudo sistematiza uma atividade acadêmica que simula didaticamente um ambiente fabril para que os estudantes de contabilidade tenham melhores compreensões dos conceitos de operações e possam correlacionar a origem dos fatos fabris com os devidos registros contábeis. Como campo de estudo estruturou-se a simulação de uma fábrica de pequenos blocos de anotações em aula de administração de operações em uma Universidade Pública localizada no Triângulo Mineiro. Primeiro faz-se a compreensão dos processos, definição dos documentos de gestão, o estudo da influência do layout, os estoques, a coleta de tempo de fabricação e dos fluxos das operações. Com base em uma situação inicial foram pesquisadas e implantadas melhorias no processo produtivo que pudessem propiciar benefícios para a fábrica como um todo. Com a aplicação de técnicas de gestão da manufatura percebeu-se uma diminuição considerável do tempo de fluxo de produção e um melhor desempenho das pessoas, por meio de operadores multifuncionais, fato que ocasionou a diminuição da ociosidade e do desbalanço da produção entre os postos de trabalho. Por conseguinte, conclui-se que a didática possibilitou aos acadêmicos um melhor conhecimento prático do controle da manufatura e suas relações contábeis e financeira. Foi possível identificar, mesmo que academicamente, a origem das informações e das diversas sistemáticas da manufatura e como o contador poderá estar realizando os respectivos registros contábeis.

Palavras-chave: Gestão da manufatura; Ensino em administração de operações; Registros contábeis.
\end{abstract}

* Universidade Federal de Uberlândia - UFU. Faculdade de Gestão e Negócios - FAGEN. Professor Adjunto. Doutor em Educação nas Ciências, Mestre em Engenharia da Produção, Administrador Universidade Federal de Uberlândia - UFU. Faculdade de Gestão e Negócios - FAGEN. Departamento de Operações e Sistemas. E-mail: chadaveiga@gmail.com .

** Universidade Federal de Uberlândia. Faculdade de Ciências Contábeis. Graduada do Curso de Ciências Contábeis. E-mail: marcella2106@gmail.com .

*** Universidade Federal de Uberlândia. Faculdade de Ciências Contábeis. Graduada do Curso de Ciências Contábeis. E-mail: brunacsdiniz@gmail.com .

**** Universidade Federal de Uberlândia. Faculdade de Ciências Contábeis. Graduada do Curso de Ciências Contábeis. Universidade Federal de Uberlândia. E-mail: 16gabriella@gmail.com . 


\title{
UNDERSTANDING MANUFACTURING PROCESS AND THEIR ACCOUNTING IMPLICATIONS BY DIDACTIC SIMULATION MEDIATION
}

\begin{abstract}
This study systematizes a didactic activity that simulates a factory environment so that accounting students can improve their understanding of the concepts of operations and can correlate the factory origin accounting facts with the proper accounting records. As a field of study, the simulation of a small note-book factory was structured in an operations management class at a Public University located in the Estate of Minas Gerais. First is the understanding of the processes, definition of the management documents, the study of the influence of the layout, the inventories, the collection of time of manufacture and the flows of the operations. Based on an initial situation, improvements in the production process were researched and implemented that could provide benefits for the plant as a whole. With the application of manufacturing management techniques, there was a considerable reduction in production flow time and better utilization of people through multifunctional operators, which led to a decrease in idleness. Therefore, it is concluded that didactics allowed the academics a better practical knowledge of the control of production and its accounting and financial relations. It was possible to identify, even if academically, the data origin and the various manufacturing routines and how the accountant may be performing the respective accounting records.
\end{abstract}

Key words: Manufacturing management; operations administration teaching; accounting.

\section{INTRODUÇÃ̃o}

A realização de atividades que oportunizam vivências, mesmo que acadêmicas dos diversos setores que fazem parte característica de uma organização empresarial, contribuem para o processo de tomada de decisão gerencial e, consequentemente, para a formação dos profissionais na área de gestão.

$\mathrm{Na}$ área de gestão a sistemática de aula mais utilizada ainda é a expositiva dialogada, liderada tipicamente pelo docente e a apresentação de seminários. Ainda se observa que há um desalinhamento, por parte dos acadêmicos, quanto aos objetivos de avaliações dos conteúdos abordados e as aprendizagens que esta não compreensão ocorre por sua apática ou até mesmo o seu alheamento (VASCONCELOS, 2017). Didáticas dinâmicas são técnicas que visam o estímulo à participação dos acadêmicos nos temas, sendo que sua realidade se mostra contrária a esta perspectiva pedagógica. Ainda o mesmo estudo demonstra que os estudantes que vivenciam este tipo de didática sentem-se despreparados quanto a autonomia e indendência (seria independência?) para o aprendizado.

A experiência, mesmo que vivencial simulada, da utilização dos recursos produtivos oportuniza aprendizados para compreender como podem ser realizadas as coletas e análise de dados fabris e a partir destes transformar em informações contábeis, como estes contribuem para a compreensão e nos aspectos de análise da gestão (VEIGA; ZANON; ZUCATTO, 2014). 
O presente trabalho aborda a implantação de uma fábrica didática de blocos de anotações cujos processos foram realizados por estudantes de uma turma do curso de ciências contábeis com o intuito de analisar os processos industriais, identificar e implantar melhorias no processo produtivo e, a partir destes dados, realizar a análise das mesmas e suas implicações no registro contábil.

Segundo Menegat e Borella (2016), o MRP é um sistema utilizado para planejamento do estoque, o qual permite a criação de uma sequência de processos para os produtos, que possibilitam, um menor custo de armazenamento e de compras, facilitam a administração dos estoques por produto e do lead time.

O MRP utiliza de uma filosofia de planejamento, com o propósito de assegurar a disponibilidade da matéria prima, isto é, suprir ou produzir as quantidades necessárias com antecedência. Assim, calcula-se o quanto será preciso de cada componente para a fabricação do produto final.

No estudo em questão foi estruturada uma fábrica de blocos de anotações, cujo sistema de manufatura era por lote de fabricação, sendo composta por cinco pessoas no processo fabril, bem como as funções administrativas, logística interna e controle de estoque. Depois de realizadas as rodadas de fabricação, observou-se que a produção apresentava lead time variado, volume maior de pessoal do que a demanda, presença de fila no processo, flexibilidade média e pausas na produção por espera.

A gestão da fábrica era realizada por um setor denominado de PCP (planejamento do controle de produção), que consiste em uma equipe de trabalho cuja ação está centrada no gerenciamento dos recursos operacionais da fábrica envolvendo o planejamento, a programação e o controle dos fluxos e das quantidades previstas a serem produzidas e as realizadas.

Ainda cabe salientar sua característica inter-relacional, pois este setor emite as ordens de fabricação e de montagem, além de coordenar o processo produtivo com os demais setores da fábrica. Assim, as ações da equipe do PCP, muitas delas apoiadas pelo MRP, fornecem suporte à gerência quanto à tomada de decisões e como gerenciar as metas produtivas. Também é responsável por implantar melhorias operacionais com o objetivo de aprimorar a utilização dos recursos.

Diante do exposto, este trabalho tem a finalidade de retratar como o entendimento da rotina fabril pode ter seus resultados contabilizados e, por meio do aprendizado adquirido em aulas conceituais, aplicar na prática fabril algumas adaptações e reflexões que serão essenciais na vida cotidiana profissional. Ademais, ao longo do estudo é apresentado o referencial teórico, a metodologia utilizada, a sistemática didática da aula e, ao final, são discutidas algumas melhorias para o processo produtivo implantado na fabricação dos blocos e suas implicações nos registros e interpretações contábeis.

\section{REVISÃO DE LITERATURA}

A revisão de literatura subdivide-se em dois tópicos, primeiramente, definem-se aspectos da Controladoria, como conceitos, objetivos e características. Posteriormente, evi- 
dencia-se os sistemas de produção MRP (Material Requirement Planning) e PCP (Planejamento e Controle de Produção) ambos orientadores do presente estudo.

\subsection{Controladoria}

Desde os primórdios, quando os homens moravam ainda em cavernas, já se identificava a necessidade da utilização de mecanismos de mensuração e controle como, por exemplo, prever a quantidade de comida para o próximo inverno (LUNKES; SCHNORRENBERGER, 2009). Dessa maneira, destaque-se que por mais que fossem práticas rudimentares, os pilares da contabilidade já estavam presentes. Assim, o surgimento do uso de controles contábeis é inerente à própria constituição e evolução humana.

Oro et al. (2009) argumentam que o aparecimento da controladoria ocorreu no início do século XX cujo papel primordial é exercer a função de base para apoiar o gestor em atividades de controle e planejamento de gestão, demandando sempre de um eficaz sistema de informação para otimizar os processos empresariais e atingir as metas de resultados esperados. Schmidt e Santos (2006) destacam quatro fatores que influenciaram o surgimento da controladoria: i) o aumento da complexidade das organizações, ii) globalização dinâmica dos mercados, iii) elevação das fontes de capitais e iv) das influências das relações governamentais.

Figueiredo e Caggiano (2006) afirmam que a finalidade da controladoria é disponibilizar informações mais acuradas ao processo decisório relativo à gestão econômica de uma corporação. Como corrobora Padoveze (2005, p.1), "a controladoria se configura como uma unidade administrativa, com estrutura própria, que, por meio da utilização maciça da teoria contábil, acoplada aos conceitos necessários das demais ciências, assim proporcionando uma visão holística dos negócios".

Como as diversas áreas do conhecimento apresentam suas funções específicas, a controladoria também as tem. Autores como Lunkes e Schnorrenberger (2009), Lunkes et al. (2009), Oliveira, Júnior e Silva (2009), Figueiredo e Caggiano (2006), Nakagawa (1995) e Moreira (2012), resumem a controladoria quanto às funções de planejamento e de controle. O termo planejamento é usado para atestar como uma empresa direciona um conjunto de decisões sequenciais para a realização da sua missão e propósitos, a fim de produzir resultados desejáveis atentando-se sempre a evitar ações inadequadas. Já quanto ao controle, ela tem a função de verificação do cumprimento das programações conforme os padrões e recursos definidos anteriormente. Em outra perspectiva, Padovere (2005), Giongo e Nascimento (2005), Figueiredo e Caggiano (2006), Lunkes et al. (2009) complementam quanto ao sistema de informação e execução.

Lourensi e Beuren (2011) ao analisarem a inserção da controladoria e como a mesma vem sendo conceituada nas teses defendidas no programa de pós-graduação da FEA/USP no período de 1997 a 2006, constatou-se que 56\% dos autores a relacionam como meio de avaliação de desempenho, enquanto $33 \%$ ao planejamento, demonstrando que na produção acadêmica ainda há uma dificuldade de conceituar os objetivos e práticas da controladoria.

Nos processos de gestão, Giongo e Nascimento (2005) afirmam que a controladoria é responsável pela definição de objetivos quanto aos controles internos, planejamento 
estratégico e operacional, na integração dos mecanismos produtivos desde os ciclos de entrada, transformação e saídas, assim como fornece os dados para os sistemas de informação. Diante disso, ela busca a sinergia das etapas empresariais para concretizar os resultados estipulados pela alta administração.

Bianchi (2005) argumenta que a controladoria atua de forma sistemática em todo o processo com a finalidade de integrar as partes relacionadas a fim de garantir que os gestores tenham um resultado otimizado. Nessa perspectiva, tem-se que a mesma estabelece um papel fundamental de ligação entre todas as dimensões de controle, como o operacional e estratégico, com o sistema de informação gerencial e com os controles internos, buscando a eficácia organizacional, desse modo, oferecendo um respaldo do que realmente está acontecendo em toda corporação.

Portanto, como abordado, é primordial para o campo empresarial a atuação da controladoria, visto que é intermediadora na tomada de decisões relevantes na busca da concretização de objetivos. Bianchi, Backes e Giongo (2016) reiteram que a adoção da controladoria pelo processo de envolvimento das pessoas em todos os níveis de uma organização, contribui para o equilíbrio e harmonia organizacional proporcionando melhor relação com as dificuldades que possam existir assim como para a obtenção e análise de resultados significativos ao processo de tomada de decisão gerencial.

\subsection{Sistema de produção com uso do MRP e as ações do PCP}

O Planejamento das necessidades materiais, também conhecido como MRP - Material Requirement Planning - pode ser definido como uma sistemática em que é possível fazer o planejamento das demandas de produção de uma empresa, bem como a necessidade de compra de componentes (SANTOS; NOBREGA, 2016). Do ponto de vista de Veiga, Zanon e Zucatto (2014) o MRP é uma forma de cálculo para estabelecer a necessidade de comprar materiais e quantidades de materiais para a fabricação de um ou vários produtos manufaturados. Os autores afirmam ainda que após a definição das necessidades, há a liberação de ordens de fabricação, montagem ou de compras.

Segundo Carmelito (2008) um conceito mais amplo do MRP e que leva a mesma lógica é o MRP II - Manufacturing Resources Planning - que além das quantidades e momentos de aquisição ou fabricação de cada item, são calculados e planejados os recursos a serem utilizados, como a capacidade de máquina, os recursos humanos necessários, os recursos financeiros, entre outros. Fernandes e Filho (2010) apontam que o MRP demanda uma definição consistente de alguns parâmetros, como o tamanho do lote, os estoques de segurança e o lead times observados no processo. Com essas informações todos os recursos que a empresa possui em mãos podem ser controlados de modo a atender fielmente às demandas e ao prazo de entrega aos clientes.

Segundo Ribeiro et al. (2015) o papel do MRP II é apoiar a decisão sobre a quantidade e o momento do fluxo de materiais em condições de demanda e serviços. Pois tal método permite que as empresas calculem os materiais dos diversos tipos que serão necessários, e em que momentos os utilizarem, garantindo que sejam providenciados a tempo, para que se possam executar os processos de manufatura. 
Apoiados por esta sistemática de cálculo a área de Planejamento e Controle de Produção - PCP realiza a gestão do processo fabril bem como a utiliza como ferramenta de suporte a tomada de decisões operacionais (ERDMANN, 1994).

Planejamento e Controle de Produção pode ser compreendido como: o primeiro termo refere-se ao ato de busca e preparação de informações que é feito antes da produção e permite definir o que deve ser produzido, em que quantidade e com quais recursos; o segundo utiliza-se do planejamento como orientação para suas ações e como fonte de dados; o terceiro e último termo, as atividades de controle, são mecanismos de verificação das atividades, tanto naquilo que se entende por planejamento como programação (FLEURY, 1983).

O PCP torna-se como um setor tático e tem como objetivo estratégico para ultrapassar os desafios da competitividade entre as empresas. O PCP é responsável por monitorar todos os aspectos do processo produtivo desde a mão de obra a gerenciamento de matérias primas e bom funcionamento de máquinas, e dessa forma garantir boa relação com todos os setores da organização (ANTUNES; SEHNEM; LIMA, 2014). Assim, o PCP deve se preocupar em responder questões fundamentais para um bom funcionamento dos sistemas produtivos.

Segundo Hekis (2013), para que o PCP consiga cumprir com o planejamento é importante que as informações entre o PCP e os diversos setores da empresa que compõem o processo produtivo sejam inter-relacionadas facilmente, e mais corretas possíveis, para que se evite omissão de dados relevantes.

Enfim, o PCP, a partir dos relacionamentos entre as diversas áreas da organização e do fluxo de informações, consegue auxiliar o gestor no desempenho das tarefas de produção (EDMILSON, 2008).

\section{Procedimentos Metodológicos}

No presente estudo como não se pretende documentar ou realizar comparações entre as coletâneas de divulgação científica, mas sim analisar com maior profundidade as possibilidades de uma aula prática de operações industriais, optou-se em adotar o estudo de caso (YIN, 2006). Conforme Prodanov e Freitas (2013) esse tipo de pesquisa permite novas descobertas de aspectos que não foram analisados previamente, assim como proporciona um detalhamento maior, dentro de um contexto específico.

No primeiro momento, foram desenvolvidas aulas teóricas em uma sala de aula do terceiro período no horário matutino do curso de Ciências Contábeis de uma Universidade Pública localizada no Triângulo Mineiro, conforme ilustrado na Figura 1, e algumas semanas depois, aulas práticas simuladas em um contexto fabril de produção de blocos. A coleta de dados ocorreu nas aulas dos dias 14, 15 e 28 de abril de 2016, quando das ações didáticas do funcionamento de uma fábrica sobre a orientação do professor do componente curricular de Administração de Operações. Como técnica de coletas de dados, pode ser caracterizada como de fonte primária, realizada por meio de observação direta semiestruturada com registro dos dados em diário de campo (MARTINS, 2006). 

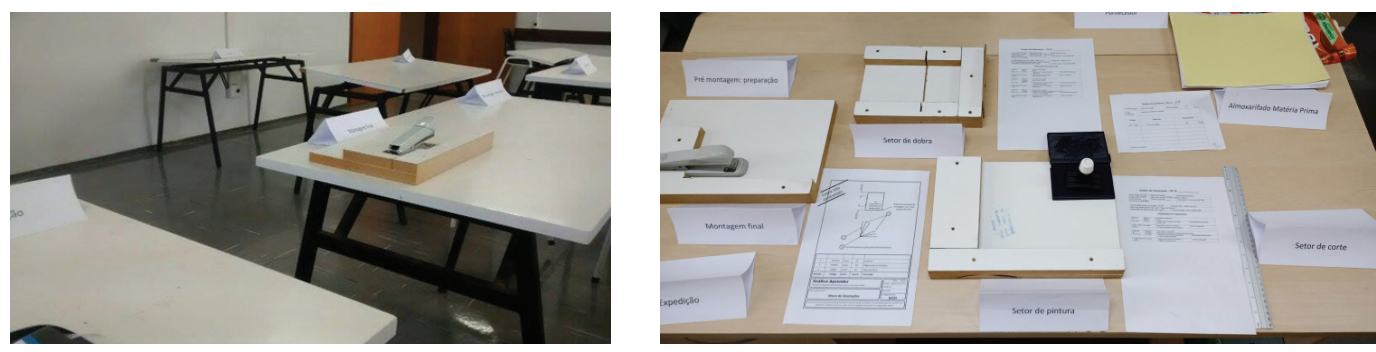

Figura 1. Ambiente parcial de sala de aula e apresentação esquemática da fábrica simulada.

Fonte: Imagens capturadas pelos autores.

A pesquisa-ação foi utilizada pelo fato dela oportunizar que o pesquisador e os demais participantes de uma pesquisa educacional tenham liberdade de interagir diretamente na ação e realizar os ajustes necessários para que o objetivo da mesma seja atingido ou para que uma determinada teoria possa ser testada (THIOLLENT, 2003). Neste sentido, a pesquisa-ação oportunizou que fossem realizadas diversas ações de melhorias aos processos industriais simulados desenvolvidos em ambiente educacional, coleta de dados e observar quais foram os resultados encontrados de maneira a oportunizar análises comparativas de resultados (MACKE, 2006).

A análise dos resultados foi realizada de maneira qualitativa (GIL, 2002) por meio da construção de um quadro no qual foram descritos os principais problemas observados e outro acerca das questões de melhorias que foram implementadas ao longo de rodadas simuladas de ordens de fabricação. Para realizar a apresentação dos dados quantitativos foram elaboradas tabelas de apresentação dos resultados da ação inicial e das diversas propostas implementadas. Com base nesses dados pode ser analisado os seus resultados separadamente bem como comparar os diversos processos adotados.

\section{Procedimentos didáticos da Aula}

As organizações das ações didáticas da aula seguiram as etapas estabelecidas por Veiga e Zanon (2016) e as temáticas trabalhadas contemplam as seguintes áreas do conhecimento: produção por lote, layout, planejamento das necessidades de materiais pela sistemática de cálculo do MRP, planejamento e controle de produção (PCP), demonstração do sistema Kanban e controles de entrada e saídas de materiais e informações.

As atividades práticas foram divididas em dois momentos, na primeira etapa foi simulada uma fábrica de blocos em ambiente setorial, fazendo-se o uso de algumas mesas para representar os setores, devidamente identificados. Desse modo, o layout foi composto de nove áreas, sendo, clientes; fornecedores; setores industriais de: almoxarifado, corte, dobra, pré-montagem, montagem final e expedição e um setor administrativo de PCP (subdividido em cálculo de MRP, emissão de ordem de fabricação e emissão de ordem de compra). 
Nesse primeiro momento os assuntos abordados foram: produção por lote, layout, planejamento das necessidades de materiais (MRP), planejamento e controle de produção (PCP). Para realizar a dinâmica, os 40 alunos foram divididos em grupos de, no mínimo, três integrantes distribuídos entre os diversos setores sendo que um deles passaria a realizar a função de colaborador e os demais coletavam dados.

Cada colaborador de sua área deveria inicialmente interpretar a ordem de fabricação advinda do setor administrativo para executar qualquer tarefa, e em complemento tinham que se adaptar ao manuseio dos equipamentos.

Para o controle do processo dos blocos fez-se o uso do quadro de planejamento de reposição de materiais (MRP) e do planejamento de controle de produção (PCP), os quais revelavam, dentre outros aspectos, as necessidades de compra de novos produtos, o controle de entrega ao cliente na data prevista; sempre considerando o lead time, a capacidade de produção, o controle de estoque, capacidade da mão de obra que auxiliam no planejamento do horizonte de fabricação. Após a finalização do processo, ocorria à entrega ao consumidor final, e para satisfazê-lo foi preciso atentar-se ao controle da qualidade.

Depois de realizados alguns lotes de fabricação de blocos, os alunos identificaram pontos que necessitavam de melhorias, principalmente, ao detectar problemas na qualidade do produto ao consumidor final, tempo ocioso de mão de obra, atrasos na entrega de matérias primas. Nessa perspectiva, a segunda etapa prática constituiu na resolução dessas falhas.

Para solucionar os erros na linha de produção e aperfeiçoar sua capacidade, testaram-se diferentes procedimentos. O primeiro método adotado foi o lote de produção igual ao lote de transferência. Nesse processo, o tempo de produção do papel branco foi de 03'37' (3 minutos e 37 segundos) e do papel colorido (capa) foi de 02'49". Desse modo, com a alteração do sequenciamento do processo produtivo com a Regra de Johnson, a qual dentre outras atribuições, minimiza o lead time total de um conjunto de ordens processadas, fabricou-se um lote contendo quatro blocos o qual ocorreu à diminuição do tempo de produção (MORAIS; MENEGARDE; CANTIERE, 2009).

Para reduzir a capacidade ociosa foi testado o princípio do operador multifuncional na busca da melhoria da produtividade. Com esta ação obteve-se um tempo de processo de fabricação de 02 '35". Salienta-se que foi atingido sem que houvesse modificação nas máquinas, nos equipamentos e no produto.

Com o intuito de atingir um tempo melhor, testou-se o lote de produção diferente do lote de transferência. O lote de produção é caracterizado por uma produção empurrada, ou seja, é uma maneira de trabalho cuja produção é em decorrência de uma demanda em que os produtos são constituídos em grandes lotes, sendo fabricado o máximo possível, sem levar em consideração a necessidade do cliente. Dessa forma, ocorreram dois testes, o primeiro foi feito quatro blocos para cada dois blocos resultando em 01 ' 52 '. O segundo teste proporcionou a produção de quatro blocos de folhas brancas para cada bloco, assim reduzindo o tempo para 01 ' 41 '”.

Quanto ao lote de transferência realizou a fabricação de duas capas com quatro folhas internas, atentando-se para não alterar a máquina e nem o equipamento. Desse modo, quando se testou as diferenças entre esses lotes obteve-se um custo fixo unitário, custo de mão de obra e tempo de fabricação menor do que quando eram iguais. 
A terceira possibilidade para solucionar os problemas fabris foi adotar o sistema Kanban. Nesse processo, há um cartão baseado em lote de processamento unitário em que consiste em produzir de acordo com o ritmo do cliente, ou seja, com a velocidade do mercado, orientando os funcionários a identificar o lugar em que os materiais estão localizados (AGUIAR e PEINADO, 2007). Quando se inicia o processo Kanban é iniciado o processamento da linha. Salienta-se que a turma não fez os cálculos de Kanban. Eles foram previamente definidos pelo docente e testados a sua operacionalização pelos acadêmicos.

Com a matéria prima na linha de produção adotando-se a metodologia Kanban, aplicou em seguida a regra de Jonhson, resultando em 0'29" para a execução de um bloco, e para produção de quatro blocos, o menor tempo obtido após o teste dos outros dois mecanismos, que foi de 1'33'. Nesse sentido, constatou-se que o melhor procedimento para resolver os erros cometidos inicialmente é aplicar o sistema Kanban e a Regra de Jonhson.

Portanto, as atividades foram desenvolvidas em duas etapas práticas proporcionando a simulação de falhas que podem ocorrer em uma fábrica na prática, e como é necessário testar diferentes formas para resolvê-las, a fim de atingir a maximização e eficiência da linha de produção.

\section{ANÁlise e discussão dos ReSUltados da PESQUiSA}

O presente estudo trabalha com dados primários obtidos por meio de uma dinâmica feita em uma sala de aula do terceiro período do Curso de Ciências Contábeis de uma universidade federal que inicialmente mostra uma fábrica de blocos organizada em um processo manufatureiro sugerido pelo docente e que posteriormente a fabricação de um lote de produtos é realizada uma análise dos resultados operacionais. Diante dos fatos observados, os estudantes são estimulados a proporem melhorias a serem feitas no processo produtivo com o intuito de diminuir o tempo de fabricação dos blocos, e concomitantemente, garantir a qualidade do produto fabricado para satisfazer as necessidades dos clientes.

Com o objetivo de projetar o cumprimento da demanda para as próximas semanas de planejamento de fabricação, na oitava semana foi realizado o cálculo do MRP (Material Requirement Planning), ou seja, planejamento das necessidades materiais, funcionando como um sistema de cálculo que prevê a demanda de acordo com suas necessidades. Além do MRP, foi utilizado também o PCP (Planejamento e Controle de Produção), a qual o lead time estabelecido foi de uma semana.

Diante disso, a partir dos resultados, consegue-se observar que o planejamento corresponde ao pedido feito pelo cliente, o qual na oitava semana é iniciado a quantidade a ser demandada pelo cliente que será inserida na produção. Na nona semana, há a ocorrência do cálculo do MRP por meio do pedido do cliente, o qual é emitido a ordem de fabricação. Com isso, na décima semana há a fabricação do produto, e da décima primeira semana até a décima quarta, há uma estimativa da demanda futura, isto é, o horizonte de demanda.

\subsection{As ações operacionais da fabricação do produto}

Com o intuito de desenvolver a produção dos blocos era necessária a realização de duas operações, uma para a fabricação da capa e outra para as páginas internas. Assim, o processo 
de produção foi iniciado com o pedido do cliente, que demandou a quantidade a ser emitida de folhas, tanto brancas quanto coloridas. Dessa forma, o pedido do cliente foi recebido, sendo feito o cálculo do MRP (o qual um software forneceu informações sobre papel A4 branco e colorido, a quantidade de folhas internas e a capa do bloco), desse modo encaminhou-se para a emissão de OF (Ordem de Fabricação) e OM (Ordem de Montagem). Diante disso, o fornecedor trabalhou com entrega imediata, ou seja, com estoque de segurança igual a zero.

Posteriormente, o estoque foi para o setor de corte, responsável em cortar e dobrar os papéis. Nesse setor, encontram-se alguns problemas em relação à falta de equipamento e no que diz respeito à marcação de papel que deveria ser realizado em outro setor para proporcionar mais dinâmica na produção.

No departamento de dobra chegou à ordem de fabricação, com o que deveria ser feito com material e o que chegou para realizar a próxima operação. Posteriormente, iniciou-se a execução colocando a folha no equipamento para fazer a dobra. Dobrou-se uma única folha por vez. Depois, o conteúdo do setor de dobra foi para o setor de pré-montagem e a ordem de fabricação voltou para o setor administrativo, devido à necessidade de controle da fabricação. Logo em seguida, encaminhou-se para o setor de pintura para realizar a operação de carimbo, dessa maneira foi feito à impressão de bloco. Por último, dirigiu-se para montagem final para ser entregue conforme o pedido do cliente.

Com relação ao tempo, a fabricação ocorreu em torno de 10 minutos devido ao modo como o layout estava montado (Layout Departamental Sequenciamento por Máquina). Portanto, o tempo total de fabricação foi de 15 minutos, porém no processo produtivo identificaram-se alguns problemas, sendo eles: atraso de entrega, ociosidade na fábrica, congestionamento de pessoas, falta de comunicação entre os setores, processo de fabricação demorado, problemas de estocagem e qualidade do produto em questão.

\subsection{Considerações sobre o estudo}

Para a realização do estudo considerou-se o lote de fabricação por dia e preços fictícios. Nesse aspecto, supôs-se que a produção diária era de 100 blocos; sendo que os componentes para sua confecção possuem um custo de aquisição de $\mathrm{R} \$ 2,00$, incluso, a matéria-prima (folhas A4); grampo, para fixar as folhas; e a tinta, utilizada para o carimbo de identificação do bloco.

Sabe-se que cada operador tem o salário calculado considerando os tributos trabalhistas totalizando a R \$ 0,10 centavos por minuto. Em complemento, a matéria prima tem um custo de R $\$ 200$ a unidade. No que se refere a mão de obra direta, a indústria constatou por meio de análises na produção a necessidade de um operador por 5 minutos na linha, assim, para 100 blocos necessita-se de 500 minutos com um custo de $\mathrm{R} \$ 0,10$ centavos por minuto, totalizando um gasto de $\mathrm{R} \$ 50,00$ por operador.

No processo produtivo, tem-se um operador no setor de dobra, corte, pintura, montagem e almoxarifado, desse modo, considerando o valor calculado anteriormente de $\mathrm{R} \$$ 50,00 vezes os cincos funcionários dispõem-se de $\mathrm{R} \$ 250,00$ de mão de obra direta. Cabe destacar também que a máquina de corte tem um custo de aquisição de $\$ 10.000$ com vida útil de 5 anos e taxa de depreciação de $10 \%$ ao ano. 
Na figura 2 são apresentados os custos conforme cada rodada de fabricação, já considerando as modificações propostas a fim de, por exemplo, diminuir o tempo de produção. Conforme os dados nela apresentados, para a produção de 100 blocos obteve-se custo total diário de $\mathrm{R} \$ 459,71$. Nesse contexto, para o custo unitário divide-se o valor do custo total pela quantidade produzida, ou seja, $\mathrm{R} \$ 4,59$ por unidade. A indústria determinou baseada em pesquisa de mercado e relatórios gerenciais, a precificação de venda em $\mathrm{R} \$ 5,50$. Esse valor proporciona $20 \%$ de margem de contribuição para cumprir com os gastos referentes a impostos, vendas, e ainda, gerar lucro. Devido às delimitações deste estudo não serão debatidas as estratégias de precificação.

Posteriormente ao cálculo do custo produtivo, deu-se início às modificações quanto ao layout, metodologias gerenciais e qualidade dos produtos, todas identificadas devido ao tempo ocioso na linha de produção na primeira rodada. No intuito de enxugar o layout para reduzir o tempo ocioso aproximou-se os setores, sendo que o setor de montagem final se localizou a frente do setor de dobra, o de dobra a direita do almoxarifado e a esquerda do de corte e, por fim, o setor de pintura próximo a montagem para finalização do produto.

Optando-se pelo início com a folha branca e novo layout, o tempo de produção total diminuiu para 3'37'. Diante disso, utilizou-se da prática do lote de produção empurrada, isto é, operando com material necessário para a confecção de acordo com a previsão de demanda (BARCO; BARBIN, 2008). Assim, observou-se que o custo total diário se reduziu para R\$ 378,21 e mantendo-se o mesmo preço de vendas a margem de contribuição do produto aumenta de $20 \%$ para $31 \%$. Com a intenção de testar outra alternativa para otimizar a linha de produção, priorizou-se a folha colorida (capa), baseado na regra de Johnson, ou seja, inicia-se a operação com o menor tempo de produção. Nesse cenário diminuiu-se o tempo para 2'49", com custo total diário para $\mathrm{R}$ \$ 334,21 e unitário $\mathrm{R}$ \$ 3,34. Comparando-se com a produção iniciada com a folha branca ganhou-se uma diminuição de custos de $27 \%$.

\begin{tabular}{|c|c|c|c|c|c|c|c|}
\hline R7 & R6 & R5 & R4 & $\mathbf{R 3}$ & $\mathbf{R 2}$ & R1 & Rodadas / custos \\
\hline 66,50 & 70,50 & 76,00 & 117,50 & 124,50 & 168,50 & 250,00 & Mão de obra \\
\hline 5,50 & 5,50 & 5,50 & 5,50 & 5,50 & 5,50 & 5,55 & Depreciação (1) \\
\hline 4,16 & 4,16 & 4,16 & 4,16 & 4,16 & 4,16 & 4,16 & Depreciação (2) \\
\hline 200,00 & 200,00 & 200,00 & 200,00 & 200,00 & 200,00 & 200,00 & Matéria prima \\
\hline 276,21 & 280,21 & 285,71 & 327,21 & 334,21 & 378,21 & 459,71 & Total \\
\hline 2,7621 & 2,8021 & 2,8571 & 3,2721 & 3,3421 & 3,7821 & 4,5971 & Unitário \\
\hline
\end{tabular}

Figura 2 - Demonstração das contabilizações feitas no Estudo de Caso

Depreciação (1): Depreciação Acumulada máquina de corte, Depreciação (2): Depreciação Acumulada Máquina de grampo, $\mathrm{Rn}=$ significa rodadas produtivas.

Fonte: elaborado pelos autores. 
Aproveitando as melhorias ainda no layout atribuiu-se ao operador da pintura, que tenha ociosidade de tempo, a função de auxílio ao setor de corte. Desse modo, tornando-se operador multinacional o qual proporcionou a redução do tempo de ociosidade entre as áreas.

Em outra perspectiva, adotando-se a dinâmica de lote de produção diferente de lote de transferência, ou seja, planeja-se 4 blocos, mas se produz e transfere de dois em dois para o resto da linha, obteve-se a diminuição do tempo produtivo para 2'35". É oportuno retratar que o custo total diário com as modificações até o momento totalizou-se em R\$ 327,21, sendo o unitário de R\$3,27.

A última etapa do processo foi conduzida pelo docente, o qual apresentou os conceitos acerca do pensamento enxuto. Uma primeira ação foi quebrar o lote de produção diferente do lote de transferência (produz 4 blocos, mas faz a transferência de dois em dois), sendo que a produção de 100 blocos gerou custo total de $\mathrm{R} \$ 285,71$, e custo unitário de 2,86. Alterando a dinâmica para produção de 4 blocos, mas com transferência de 1 em 1 , o tempo reduz para 1'41'. Cabe salientar que esta sistemática exige um sistema de controle dos produtos em processos de fabricação com mais assertividade e qualificação das pessoas na compreensão de sua importância.

Para a última análise, o docente orientou a mudança do layout e do funcionamento do método de produção puxada a partir do ritmo do cliente. Os estudantes não realizaram os cálculos de dimensionamentos de Kanbans. Eles foram orientados como eles seriam utilizados para nortear o processo de fabricação. Assim, iniciou-se o processamento da linha quando o pedido do cliente foi colocado na expedição e a partir deste setor foi iniciado o acionamento dos demais Kanbans. Dessa forma, em 0'29" temos 1 bloco e em 1'33", 4 blocos. Observou-se que fazendo uso do Kanban o custo total diário passou a ser R\$276,21 e o custo total unitário $\mathrm{R} \$ 2,76$. Com todas as mudanças, no resultado final há uma diminuição $40 \%$ no valor do custo.

$\mathrm{Na}$ perspectiva apresentada, pode-se observar que a gestão do fluxo de manufatura interfere nos resultados operacionais de uma fábrica e consequentemente nas suas capacidades de produção e de respostas ao mercado. Também foi possível verificar as correlações que estas alterações impactam na constituição dos custos e, consequentemente, para a melhoria dos seus resultados. Assim, o trabalho do contador, na visão das atividades de controladoria, conforme Siqueira e Soltelinho (2001), é compreender as diversas ações de melhorias realizadas dentro da área operacional, realizar os seus devidos registros contábeis e suas análises, bem como reportar estes dados aos gestores, via demonstrações contábeis devidamente detalhadas por meio de notas explicativas, com vistas a auxiliar na verificação da eficácia das medidas tomadas e oportunizar fatos contábeis que auxiliem a novas tomadas de decisão.

\subsection{Análise das medidas de melhorias implementadas}

Desse modo, observou-se que para corrigir os problemas analisados ao longo do processo de produção, seja para obter um melhor aproveitamento do produto, seja para proporcionar uma maior dinâmica, é preciso adotar medidas de melhorias produtivas que 
visem aprimorar cada vez o produto elaborado, as quais são: implementar um rastreamento de informações mais rígido; organizar os setores de acordo com o andamento da produção; diminuir a capacidade ociosa; investir em métodos que garantam uma melhoria contínua e a satisfação do cliente; e, sobretudo, a aplicação da padronização que é o procedimento que desenvolve e combina práticas que designam padrões para os processos que envolvam operações, sendo um instrumento administrativo que tem como finalidade melhorar o funcionamento dentro da produção (SLACK et al., 2013).

Outra melhoria analisada foi o layout com o objetivo de diminuir o tempo de fabricação do bloco. Criou-se um fluxograma de produção detalhado para uma visão da cadeia de suprimentos abrangente que inclua tanto os fluxos de informação como os de materiais entre a empresa, seus fornecedores e clientes. Um setor próximo do seu subsequente, seguindo o fluxo da produção, reduz o tempo de locomoção de um setor para outro.

Com o layout aproximado e alterando a produção para o ritmo do cliente com o uso do método Kanban e de produção puxada alcançou-se uma diminuição de custos de $40 \%$. Portanto, conclui-se que é importante para a entidade essa análise e melhoria constante, o que torna uma vantagem competitiva e como consequência aumenta os resultados positivos da empresa.

Com isso, para melhorar o desempenho da produção como um todo, além das medidas destacadas anteriormente, há também várias outras que se adotadas, garantem a satisfação tanto do fornecedor quanto do cliente. Sendo elas: identificar os defeitos por unidade, levando em consideração as reclamações dos clientes, observar o lead time do pedido e ao mesmo tempo, o tempo de fabricação do produto com o intuito de buscar um melhor rendimento na produção, analisar e questionar as entregas que ocorreram em atraso para que assim, haja mudanças internas com relação a harmonização e a elaboração, tendo em mente que deve haver um conhecimento bastante detalhado acerca dos produtos em estoque, observando também o tamanho do lote e a capacidade média da produção com a utilização de recursos.

\section{Considerações finais}

O presente estudo demonstrou a análise da simulação de uma fábrica de blocos em uma aula de administração de operações, tendo como objetivo, estudar e implantar melhorias para o processo produtivo a partir do uso destas ferramentas de gestão e verificar suas influências nos registros contábeis.

Ao decorrer do processo de fabricação foram detectadas algumas lacunas como tempo ocioso das pessoas e equipamentos, baixa qualidade do produto, demora no envio das peças para a finalização dos lotes de fabricação. Como as atividades desempenhadas eram feitas conforme as ordens de produção, nas quais se especificam quantidades, operações e materiais utilizados, sendo que as mesmas, inicialmente, não definiam o seu sequenciamento de produção, foi necessário implantar ferramentas para controlar o fluxo de materiais e os demais recursos ao longo do processo (LAURINDO, 2000). A partir da sua identificação foram testados alguns mecanismos gerenciais para solucionar os problemas vivenciados. 
Assim, foram realizadas melhorias no layout, nas regras de priorização das ordens, na forma de gestão das pessoas e na quebra dos lotes de fabricação. Diante destas ações, pode-se observar alterações relevantes nas questões de produtividade, redução do tempo total do fluxo de fabricação, manutenção do tempo de processo de cada peça e redução dos custos unitários. Esses resultados em conjunto proporcionaram a minimização das distâncias, melhor qualificação das pessoas e a eficiência operacional.

A capacidade de reconfigurar um sistema de produção existente é um fator chave para manter competitividade no ambiente de negócios de produção. Neste sentido, as contribuições deste estudo, demonstram que o profissional de contabilidade necessita realizar as devidas interpretações dos resultados das melhorias operacionais por meio dos registros e análises contábeis. Nesta perspectiva, foi possível perceber uma dificuldade inicial em verificar e compreender os fatos industriais vivenciais e correlacioná-los com as teorias propostas no curso e estudadas em outros componentes curriculares. Pode-se observar que as aulas práticas oportunizam vivências que tornam o aprendizado acadêmico mais dinâmico e que exige a ação interdisciplinar para a compreensão de todos os fatos ocorridos (MOREIRA et al., 2013).

As limitações desta pesquisa referem-se, inicialmente, aos dados utilizados para o estudo que em alguns momentos utilizou-se da generalização e de estimativas das informações. Outro aspecto é quanto aos achados serem para uma indústria fictícia. Diante disso, não se sabe se os resultados poderiam ser melhorados em uma empresa verídica, haja visto as características de cada empresa. Sugere-se, para estudos futuros, adotar os diferentes mecanismos para outros tipos de indústrias a fim de proporcionar a comparabilidade dos resultados e adotar outros instrumentos gerenciais de maneira a serem vivenciados diferentes cenários de estudos.

Ao realizar atividades didáticas dinâmicas de ambientes industriais em aula, possibilita aos estudantes a compreensões práticas das teorias estudas e, a partir dos dados primários coletados na aula, construir conhecimentos interdisciplinares semelhantes a vida real. Como contribuição para estudos futuros, sugere-se que sejam realizados processos operacionais mais complexos e com uso de softwares comerciais de maneira a realizar uma segunda análise em ambientes mais complexos.

\section{REFERÊNCIAS}

AGUIAR, G. F.; PEINADO, J. Compreendendo o Kanban: um ensino interativo ilustrado. Revista da Vinci, Curitiba, v. 4, n. 1, p. 133-146, 2007.

ANTUNES, L. S.; SEHNEM, S.; LIMA, M. A. Análise do planejamento e controle de produção no setor de usinagem, corte e conformação em indústria Metalmecânica. Revista de Gestão e Tecnologia, v. 4, n. 1, p. 22-34, 2014.

BARCO, C. F.; BARBIN, F. Análise dos sistemas de programação e controle da produção. In: ENCONTRO NACIONAL DE ENGENHARIA DE PRODUÇÃO, 28., 2008, Rio de Janeiro. Anais eletrônicos... Rio de Janeiro: ENEGEP, 2008. Disponível em: http://www.abepro.org.br/publicacoes/ . Acesso em: 16 maio 2017. 
BEUREM, I. M. Como elaborar trabalhos monográficos em contabilidade. São Paulo: Atlas, $3^{\mathrm{a}}$ ed., 2008 .

BIANCHI, M. A controladoria como um mecanismo interno de governança corporativa e de redução dos conflitos de interesse entre principal e agente. 2005. 159 f. Dissertação (Mestrado em Ciências Contábeis) - Programa de Pós - Graduação em Ciências Contábeis. Universidade do Vale do Rio dos Sinos, São Leopoldo, Porto Alegre. 2005.

BIANCHI, M.; BACKES, R. G.; GIONGO, J. A participação da Controladoria no processo de gestão organizacional. Revista Contexto, Porto Alegre, v.6, n.10, jul./dez. 2016.

CARMELITO, R. Conceitos básicos do MRP (MATERIAL REQUIREMENT PLANNING). Disponível em: <http://www.administradores.com.br/artigos/carreira/conceit-osbasicos-do-mrp-material-requirement-planning/26507 >. Acesso em: 03 abr. 2017.

ERDMANN, R. H. Modelo organizativo para sistemas de planejamento e controle da produção. 2017. 309 f. Tese (Doutorado em Engenharia de Produção) - Programa de Pós-Graduação em Engenharia de Produção, Santa Catarina. 2017.

FERNANDES, F. C. F.; FILHO, G. M. Planejamento e controle da produção: dos fundamentos ao essencial. 1. ed. São Paulo: Atlas, 2010.

FIGUEIREDO, S.; CAGGiAnO, P. G. Controladoria: teoria e prática. 3. ed. São Paulo: Atlas, 2006.

FLEURY, P. F. Planejamento e Controle de Produção em empresas exportadoras e não-exportadoras: um estudo comparativo. Revista de Administração, v. 18, n. 4, p. 18-26, 1983.

GIONGO, J.; NASCIMENTO, A. N. O envolvimento da controladoria no processo de gestão: um estudo em empresas industriais do estado do Rio Grande do Sul. In: CONGRESSO INTERNACIONAL DE CUSTOS, 9, 2005, Florianópolis. Anais eletrônicos.. Florianópolis/SC: CBC, 2005. Disponível em: https://anaiscbc.emnuvens.com.br/anais/aRtiCle/view/2094/2094. Acesso em: 02 jan. 2017.

HÉKIS, H. R.; OLIVEIRA, I. M. P.; SILVA, A. C.; ARAUJO, J. P. F. Planejamento e controle de produção através de uma análise do fluxo informacional em empresa do ramo alimentício do município de Mossoró/RN. Revista Ciências Administrativas, v. 19, n. 1, p. 236-264, 2013.

LAURINDO, F. J. B. Material Requirements Planning: 25 anos de história, uma revisão do passado e prospecção do futuro. Revista Gestão e Produção, São Carlos, v.7, n. 3, p. 320-337, dez. 2000.

LOURENSI, A.; BEUREN, I. M. Inserção da Controladoria em Teses da FEA/USP: uma análise nas perspectivas dos aspectos conceitual, procedimental e organizacional. Revista Contabilidade Vista \& Revista, Belo Horizonte, v. 22, n. 1, p. 15-42, jan./mar. 2011.

LUNKES, R. J.; SCHNORRENBERGER, D. Controladoria: na coordenação dos sistemas de gestão. 1. ed. São Paulo: Atlas, 2009.

LUNKES, R. J.; SCHNORRENBERGER, D.; GASPARETTO, V.; VICENTE, E.F.R. Considerações sobre as funções da controladoria nos Estados Unidos, Alemanha e Brasil. Revista Universo Contábil, Blumenau, v. 5, n.4, p. 63-75, out./dez. 2009.

MENEGAT, O.; BORELLA, M. R. C. Impacto dos conceitos do MRP no gerenciamento de estoques numa empresa metalúrgica do polo metal-mecânico da serra gaúcha. In: ENCONTRO NACIONAL DE ENGENHARIA DE PRODUÇÃO, 36., 2016, Paraíba. Anais eletrônicos... Paraíba: ENEGEP, 2016. Disponível em: http://sistema.semead.com.br/16semead/resultado/trabalhosPDF/375.pdf. Acesso em: 01 jan. 2016. 
MORAIS, M. F.; MENEGARDE, J. K. J.; CANTIERE, P. C. Regras de prioridade e critérios de desempenho adotados em problemas de programação da produção em ambientes flow shop. In: ENCONTRO DE PRODUÇÃO CIENTÍFICA E TECNOLÓGICA, 4., 2009, Paraná. Anais eletrônicos... Paraná: FECILCAM, 2009. Disponível em:http://www.fecilcam.br/nupem/anais_iv_epct/ PDF/engenharias/05_MORAIS_MENEGARDE_ANTIERE.pdf. Acesso em: 16 maio $201 \overline{7}$.

MOREIRA, D. A. Administração da produção e operações. 2. ed. São Paulo: Cengage Learning, 2012.

MOREIRA, R.L. et al. A importância da informação contábil no processo de tomada de decisão nas micro e pequenas empresas. Revista Contemporânea de Contabilidade, Florianópolis, v.10, n.19, p.119-140, jan. /abr. 2013.

NAKAGAWA, M. Introdução à controladoria. 1. ed. São Paulo: Atlas, 1995.

OLIVEIRA, L. M.; JUNIOR, J. H. P.; SILVA, C. A. S. Controladoria Estratégica. São Paulo: Atlas, 2009.

ORO, I. M.; DITTADI, J. R.; CARPES, A. M. S.; BENOIT, A. D. O perfil do profissional de controladoria sob a ótica do mercado de trabalho brasileiro. Revista Pensar Contábil, Rio de Janeiro, v. 11, n. 44 , p. $5-15$, abr./jun. 2009.

PADOVEZE, C. L. Controladoria Avançada. 1. ed. São Paulo: Pioneira Thomson Learning, 2005.

PRODANOV, C.C.; FREITAS, E.C. Metodologia do trabalho científico: métodos e técnicas da pesquisa e do trabalho acadêmico. 2. ed. Rio Grande do Sul: Feevale, 2013.

RIBEIRO, M. Y. D.; CARMO, E. P. D.; LOBATO, B. C.; LOPES H. D. S. Aplicação do MRP como ferramenta para o planejamento e controle da produção em uma indústria de cabos elétricos de alumínio. In: ENCONTRO NACIONAL DE ENGENHARIA DE PRODUCÃO, 25, 2015, Fortaleza. Anais eletrônicos... Fortaleza/CE: ENEGEP, 2015. CD-ROM.

SLACK, N. et al. Gerenciamento de operações e de processos: princípios e práticas de impacto estratégico. 2. ed. Porto Alegre: Bookman, 2013.

SANTOS, E. B. C.; NOBREGA, D. D. Análise dos desperdícios existentes e do respectivo controle via mrp na produção de alimentos direcionados para recém-nascidos e lactentes em ambiente residencial. In: ENCONTRO NACIONAL DE ENGENHARIA DE PRODUCÃO, 34, 2016, João Pessoa. Anais eletrônicos... João Pessoa/PB: ENEGEP, 2016. Disponível em: http://www.abepro. org.br/biblioteca/TN_STO_226_318_30561.pdf. Acesso em: 15 abr. 2017

SCHMIDT, P.; SANTOS, J. L. Fundamentos de Controladoria. 1. ed. São Paulo: Atlas, 2006.

VASCONSELOS, Y. L. Ensino de Administração: Análise das Técnicas de Exposição e

Seminário. ReFAE - Revista da Faculdade de Administração e Economia, v. 8, n. 2, p. 125-154, 2017.

VEIGA, C. H. A., \& ZANON, L. B. Atividade de interação com integração de aprendizagens: uma didática para ambientes de ensino dinâmicos. Curitiba: Appris, 2016.

VEIGA, C. H. A.; ZANON, L. B.; ZUCATTO, L. C. Ação didática de ensino simulado: uma pesquisa-ação acerca do conteúdo de MRP. Administração: Ensino e Pesquisa, v. 15, n. 2, p. 381-414, 2014.

Submetido em: 7-3-2018

Aceito em: 4-5-2021 